\title{
Structural stability of NaPON glass upon heating in air and nitrogen
}

Georgiana Laura Paraschiv ${ }^{1}$, Francisco Muñoz ${ }^{2}$, Lars R. Jensen ${ }^{3}$, Yuanzheng Yue ${ }^{1, *}$, Morten M. Smedskjaer ${ }^{1, *}$

${ }^{1}$ Department of Chemistry and Bioscience, Aalborg University, Denmark

${ }^{2}$ Institute of Ceramics and Glass (CSIC), Madrid, Spain

${ }^{3}$ Department of Materials and Production, Aalborg University, Denmark

*Corresponding authors. E-mail: mos@bio.aau.dk (M.M.S.), yy@bio.aau.dk (Y.Z.Y.)

\begin{abstract}
The thermal stability in air and nitrogen of an oxynitride NaPON glass with high nitrogen content $(\mathrm{N} / \mathrm{P}=0.5)$ has been investigated with regards to its structural evolution with temperature. The glass transition temperature $\left(T_{\mathrm{g}}\right)$ of the powdered glass is found to decrease upon oxidation, especially when the treatment temperature $\left(T_{\mathrm{a}}\right)$ is larger than the $T_{\mathrm{g}}$ of the original oxynitride glass. Upon isothermal oxidation, crystalline metaphosphate forms at the interface of the oxide layer as the dominant phase in both the powder and bulk samples, as detected by Raman spectroscopy and X-ray diffraction. A new deconvolution scheme of Raman spectra is proposed, involving a structural model proposed to account for the in situ high temperature changes of the local structural groups. A distinction is made between different oxynitride $Q^{\mathrm{n}}(\mathrm{P}, \mathrm{N})$ tetrahedral sites, and two separate bands related to tri-coordinated nitrogen speciation $\left(\mathrm{N}_{\mathrm{t}}\right)$ are distinguished in the oxidized NaPON glass. $\mathrm{N}_{\mathrm{t}}$ groups are connected to either one oxygen or one nitrogen, resulting in two separate Raman bands. The position and area of these $\mathrm{N}_{\mathrm{t}}$-related peaks exhibit an opposite trend with temperature in air and $\mathrm{N}_{2}$. Furthermore, the Raman results imply a thermally driven depolymerization of the oxynitride sub-structure, which could involve a nano-scale phase separation of the nitrogen-involved structure network. In terms of technological applications, this work suggests that the oxynitride glasses should be used in the temperature range up to the glass transition temperature, above which the structural stability is lost.
\end{abstract}




\section{Introduction}

The incorporation of nitrogen in oxide glasses improves their physical, chemical, mechanical, and thermal properties, as the partial anionic substitution of trivalent nitrogen for divalent oxygen leads to a higher bond density within the glassy network [1]. The oxynitride network has a higher degree of interconnectivity and covalent bonding [2] as compared with their analogous oxide glasses. Furthermore, the Coulombic forces between the constitutive tetrahedra and modifying cations increase [3].

An intergranular oxynitride glass phase has been observed in $\mathrm{Si}_{3} \mathrm{~N}_{4}$-based ceramics used at high temperatures in air, limiting the mechanical performances [4]. As such, it is important to understand the oxidation resistance of nitride and oxynitride materials. Previous studies have suggested that crystalline $\mathrm{Si}_{2} \mathrm{~N}_{2} \mathrm{O}$ exhibits inferior oxidation stability compared to amorphous $\mathrm{SiO}_{\mathrm{x}} \mathrm{N}_{\mathrm{y}}$. This was explained by a more complex oxidation process of the latter, involving a mixed reaction/diffusion rate-limiting mechanism caused by gradual replacement of nitrogen with oxygen in the network structure due to oxygen diffusion [5]. Glass oxidation resistance has been the subject of different studies related to silicate-based oxynitride [6] and in particular silico-aluminate-based oxynitride systems [4], [7]-[10], in which the fractional weight gain (due to loss of nitrogen and gain of oxygen) are quantified using thermo-balances, or by ellipsometry through monitoring the thickness of oxynitride films on $\mathrm{SiO}_{2}$ substrates [11]. Partial thermal decomposition of oxynitride glasses has been observed before the initiation of oxidation, causing an initial weight loss reported for Ln-Si-A-O-N [12] and Ca-Si-Al-O-N [4] glasses, especially at lower oxidation temperatures. The resistance to oxidation depends on the glass composition and structure, and increases with the nitrogen content and decreases with the ionic radius of the modifier cations [10], [12]. Heating of oxynitride glasses to temperatures above the glass transition temperature $\left(T_{\mathrm{g}}\right)$ in air leads to the formation of a surface layer of porous oxides known as scales [10], [13], which is a result of the surface reaction of glass with oxygen coupled with outward diffusion of modifier cations. This heating process leads to both nitrogen release and simultaneous formation of voids at the internal interface, followed by the growth of the oxide layer [10]. The crystallinity of the oxide layers and the oxidation resistance depend on the glass composition [4].

Excluding the silicate-based oxynitride systems, the oxidation resistance of other oxynitride glass systems is poorly studied. The oxidation behavior of a phosphorus oxynitride glass has been investigated using thermogravimetry (TG) and differential scanning calorimetry (DSC) and manifests as a two-step oxidation process [14]. As such phosphorous oxynitride glasses have potential applications, e.g., as hermetic 
glass-metal seals [15], it is important to know how these materials respond to atmosphere at elevated temperature. Nitridation modifies the structure of phosphate glasses in the manner that nitrogen enters the oxide network in either tri-coordinated $\left(\mathrm{N}_{\mathrm{t}}\right)$ form, directly creating cross-linkages in the phosphate network, or in di-coordinated $\left(\mathrm{N}_{\mathrm{d}}\right)$ form, indirectly cross-linking by forcing the formation of P-O-P linkages between the phosphate chains. As a result, the $\mathrm{PO}_{4}$ structural units transform into $\mathrm{PO}_{4-\mathrm{y}} \mathrm{N}_{\mathrm{y}}$ tetrahedral units (i.e., $\mathrm{PO}_{3} \mathrm{~N}$ and $\mathrm{PO}_{2} \mathrm{~N}_{2}$ ). More structural information of phosphorus oxynitride glasses has been reported in previous studies [16]-[18].

This study aims at obtaining a comprehensive understanding of the oxidation behavior of oxynitride glasses by using a sodium oxynitride phosphate glass with high nitrogen content $\left(\mathrm{NaPO}_{2.25} \mathrm{~N}_{0.5}\right)$. The changes in $T_{\mathrm{g}}$ are monitored using DSC as a probe for the degree of oxidation, since it has been established that $T_{\mathrm{g}}$ scales linearly with N/P ratio in oxynitride glasses [18]. The main purpose of this study is to detect the structural changes by the means of Raman spectroscopy and the amorphous-to-crystalline transitions via Xray diffraction (XRD) analysis. Kinetics results of oxidation process of oxynitride glasses can be found in Refs. [4], [10], [12]. Isothermal (static) treatments at temperatures $\left(T_{\mathrm{a}}\right)$ ranging from $0.9 T_{\mathrm{g}}$ to $1.35 T_{\mathrm{g}}$ are carried out in air. To evaluate the effect of surface oxidation on the structural stability, glass samples have been isothermally treated and calorimetrically and spectroscopically analyzed in both bulk and powder form. Additionally, by dynamically heating bulk glass samples in both air and $\mathrm{N}_{2}$ gas, the stability of the nitrided sites in the glass network is monitored using in situ high-temperature Raman spectroscopy. Ultimately, the deconvolution of the in situ Raman spectra allows for a structural model to be proposed that accounts for the observed structural changes.

\section{Experimental}

\subsection{Sample preparation}

$\mathrm{NaPO}_{2.25} \mathrm{~N}_{0.5}$ glass with N/P ratio was obtained from a sodium metaphosphate base composition $50 \mathrm{Na}_{2} \mathrm{O} \cdot 50 \mathrm{P}_{2} \mathrm{O}_{5}$ (in mol\%) via ammonolysis by heating 2-3 grams of glass at $1058 \mathrm{~K}$ for $2 \mathrm{~h}$ in $\mathrm{NH}_{3}$. The preparation procedure of this oxynitride glass is described in detail in Ref. [16]. $T_{\mathrm{g}}$ of this composition was previously determined to be $642 \mathrm{~K}$ [16]. Bulk samples were cut using diamond-coated saw blades and then polished in ethanol, while powder samples (with particle size range of 10-140 $\mu \mathrm{m}$, and the largest fraction at 
$\sim 40 \mu \mathrm{m}$ ) were obtained by manual grinding in a glove box under inert atmosphere. The samples were kept in containers with desiccant to avoid hydration.

The samples were then subjected to thermal oxidation experiments by heating in air at temperatures ranging from: (i) $T_{\mathrm{a}}=0.9 T_{\mathrm{g}}$ to $1.35 T_{\mathrm{g}}$ (scaled in Kelvin) for different treatment durations $t_{\mathrm{a}}=10 \mathrm{~min}$ to $20 \mathrm{~h}$ for the bulk samples; and (ii) $T_{\mathrm{a}}=0.9 T_{\mathrm{g}}$ to $1.2 T_{\mathrm{g}}$ for $t_{\mathrm{a}}=1 \mathrm{~h}$ for the powdered samples.

\subsection{Differential scanning calorimetry}

DSC measurements were performed on the pristine and heat-treated samples using a simultaneous thermal analysis instrument (STA449 F1 Jupiter, Netzsch) in order to obtain the isobaric heat capacity $\left(C_{\mathrm{p}}\right)$ curves. All the DSC measurements include baseline corrections, the reference (sapphire) scan, and the sample scan. For each sample, two runs of DSC up- and down-scans were performed at $10 \mathrm{~K} / \mathrm{min}$ and the maximum scanning temperature is about $70 \mathrm{~K}$ above $T_{\mathrm{g}}$. The second up-scan (standard scan) records the enthalpy response of a sample with a known thermal history [19]. All measurements were performed under argon flow to avoid oxidation. $T_{\mathrm{g}}$ was assigned as the onset temperature of the endothermic rise, i.e., the glass transition peak, of the $C_{\mathrm{p}}$ curves.

\subsection{X-ray diffraction}

XRD spectra were recorded on the heat-treated powdered samples. It is noted that it was not possible to acquire diffraction measurement on the post-heat treated bulk samples due to the limited mass (20-25 mg). Measurements were performed on an Empyrean diffractometer (PANalytical) using $\mathrm{Cu}-\mathrm{K} \alpha$ radiation in the $2 \theta$ range from $5^{\circ}$ to $50^{\circ}$ with a step size of $0.05^{\circ}$. Voltage and working current were $45 \mathrm{~V}$ and $40 \mathrm{~mA}$, respectively.

\subsection{Raman spectroscopy}

Raman spectroscopy measurements were performed on all samples using a Renishaw inVia micro-Raman spectrometer with a $532 \mathrm{~nm}$ diode laser as the excitation source. The spectra were acquired in the range from 150 to $1500 \mathrm{~cm}^{-1}$. The as-obtained spectra were subjected to baseline correction using a multivariate curve resolution-ALS algorithm [20], followed by area normalization using the total integrated area of the 
spectrum. Subsequently, a temperature-frequency correction was applied in order to compare the spectra acquired at different temperatures. The spectra were collected with two acquisitions of $10 \mathrm{~s}$ each.

The in situ high-temperature Raman measurements were performed using a cell with heating stage, equipped with a crystalline $\mathrm{CaF}_{2}$ transparent window, which gives a single sharp Raman signal at $321 \mathrm{~cm}^{-1}$ and thus no other interfering signal. The lack of an interfering signal from the cell top window in the spectra confirms that the laser was focused on the glass sample. Spectra were collected every $50 \mathrm{~K}$ between room temperature and $573 \mathrm{~K}$, and every $10 \mathrm{~K}$ for temperatures between 583 and $773 \mathrm{~K}$, in the range of 170 to 1500 $\mathrm{cm}^{-1}$. The heating rate was $10 \mathrm{~K} / \mathrm{min}$, and $1 \mathrm{~min}$ isotherm was applied during refocusing the laser and recording the spectra. The in situ measurements were performed in both air and $\mathrm{N}_{2}$ atmosphere The samples were approximately $0.3-0.55 \times 0.3-0.5 \mathrm{~mm}$ in size, with flat top and bottom surfaces.

The Raman bands were assigned to various vibration modes according to previously reported data for phosphate and oxynitride phosphate glasses and thin films [16], [21]-[33]. All the spectra were then decomposed into Gaussian contributions using the Fityk software, with 18 bands for each spectrum. The deconvolution was based on previously studied NaPON and LiPON glasses [16], [30], coupled with structural data obtained from ${ }^{31} \mathrm{P}$ NMR [34], [35], infrared [24], [36], and X-ray photoelectron spectroscopy [37].

\section{Results and discussion}

\subsection{Isothermal heating in air}

\subsubsection{Effect on glass transition behavior}

Isothermal heat-treatment under oxidizing conditions affects the glass transition behavior of the glass samples in both powdered and bulk form, as illustrated in Figs. 1(a,b) and 2, respectively. $T_{\mathrm{g}}$ of the $\mathrm{NaPO}_{2.25} \mathrm{~N}_{0.5}$ glass prior to oxidation treatment has previously been determined to be $642 \mathrm{~K}$ [16]. The glass transition peak (enthalpy overshoot) of the $C_{\mathrm{p}}$ curves for the heat-treated powdered glasses (Fig. 1a) becomes broader and begins at lower temperature with increasing $T_{\mathrm{a}}$. This change is attributed to a partial oxidation of the glass, as the oxynitride composition has higher $T_{\mathrm{g}}$ than the base oxide composition.

Significant changes in the glass transition are observed when $T_{\mathrm{a}}$ approaches $1.05 T_{\mathrm{g}}\left(T_{\mathrm{g}}+30 \mathrm{~K}\right)$, but generally the $C_{\mathrm{p}}$ jump during glass transition (i.e., the difference between heat capacities of the glass at $T_{\mathrm{g}}$ and supercooled liquid above $T_{\mathrm{g}}$ i.e. $\Delta C_{\mathrm{p}}$ ) becomes smaller with increasing $T_{\mathrm{a}}$ as seen in Fig. 1a. Generally, 
for a homologous glass series, the increases in $\Delta C_{\mathrm{p}}$ can be related to a decrease in glass network connectivity [38]. However, in the present work, the opposite trend is observed: $\Delta C_{\mathrm{p}}$ decreases with a slight decrease of network connectivity due to increasing $T_{\mathrm{a}}$, i.e., increasing degree of oxidation. This indicates that the observed decrease in $\Delta C_{\mathrm{p}}$ is not associated with the oxidation-induced network depolymerization.

For SiAlON and LiPbPON oxynitride glass systems, the oxidation sets in at temperatures above the softening point $\left(10^{6.6} \mathrm{~Pa} \cdot \mathrm{s}\right.$ isokom temperature) [8], [13]. Based on the dependence of glass transition temperature on isothermal heating temperature (Fig. 1b), the $T_{\mathrm{g}}$ of powdered glasses exhibit a decrease at temperatures right above the $T_{\mathrm{g}}$ of the pristine oxynitride glass, signaling the commencement of oxidation. Two regimes are thus observed for $T_{\mathrm{g}}$ as a function of $T_{\mathrm{a}}$, which are evident by the abrupt change in the slope in Fig. 1b. When $T_{\mathrm{a}}<T_{\mathrm{g}}$ of the as-prepared glass, only minor changes in $T_{\mathrm{g}}$ with $T_{\mathrm{a}}$ are observed, whereas for $T_{\mathrm{a}}>T_{\mathrm{g}}$, a decrease of up to $40 \mathrm{~K}$ is found.

In comparison, the bulk samples subjected to heat-treatment in air do not exhibit significant changes in $T_{\mathrm{g}}$ with the heat-treatment time and temperature (Fig. 2). For lower oxidation temperatures $\left(<1.0 T_{\mathrm{g}}\right)$, the $T_{\mathrm{g}}$ first decreases slightly with extending duration and then reaches a constant value. The bulk sample can maintain its original shape up to $1.35 T_{\mathrm{g}}$ (grey triangle in Fig. 2). It is evident from Fig. 2 that the oxidation of the bulk oxynitride glasses occurs at much lower rates than the powdered samples. While all the treated bulk samples experience a decrease in $T_{\mathrm{g}}$ compared to the pristine oxynitride glass, the changes in this case are smaller than $\pm 4 \mathrm{~K}$ even for the longest treatment durations, when compared to the more significant changes observed for powdered samples. This is due to the larger specific surface area of the powder, enabling a continuous oxidation through an oxidized surface layer [14]. The oxidation starts from the powder surface at elevated temperature, suggesting that oxidation is most effective in the surface region. Oxygen is expected to diffuse through and oxidize the glass network, causing a depletion of nitrogen. When $T_{\mathrm{a}}>T_{\mathrm{g}}$, glass relaxes sufficiently to enable kinetic processes such as viscous flow [39], as such the melt viscosity decreases and consequently the oxygen diffusivity increases [8]. That is, the increase in mobility of the structural species favors the oxidation in air and the crystallization in reducing atmosphere [10], [40].

\subsubsection{Effect on crystallization and structure}

Previous studies treating oxidation behavior of oxynitride glasses [4], [10], [12] have presented the overlapping effect of crystallization with oxidation. The oxidation-induced oxide layers change continuously 
with the heat treatment time and temperature [10], and the nature (amorphous/crystalline) and morphology of the oxide layer is also affected by the oxidative conditions and glass composition [12]. The oxidation process of a Yb-Si-A-O-N glass [12] was found to occur in three stages: (i) interface reaction-controlled oxidation, (ii) diffusion controlled oxidation, and (iii) final stage of oxidation with decelerated rate. The interface between the oxide scale and oxynitride glass appears to favor a degree of crystallization during oxidation in air. In consequence, the oxidation rate is reduced as the crystallization begins at the interface when the surface is oxidized [12]. Bulk crystallization of the glass can also develop during oxidation treatments, but it requires higher temperatures to overcome the higher activation energy for crystals nucleation and growth.

The oxidation-induced structural changes and crystallization of the present NaPON glass have been investigated via Raman spectroscopy (Fig. 3) and X-ray diffraction (Fig. 4). The differences between the bulk and powder heat-treated samples can be observed in the Raman spectra collected ex situ under ambient conditions (Fig. 3a,b). The assignment of the Raman bands for the corresponding metaphosphate $\mathrm{NaPO}_{3}$ glass is shown in analogy with the Raman spectra of the as-prepared sample in Fig. 3a. The spectrum of both types of glasses exhibits the characteristic vibrational modes associated with the phosphate and oxynitride phosphorus networks [22]-[24], [27], [21], [41]. For the powdered samples (Fig. 3a), heat-treatment for $1 \mathrm{~h}$ in air at $T_{\mathrm{a}}<T_{\mathrm{g}}$ induces only minor structural changes and no crystallization. These structural changes involve the decrease in the intensity of the $\mathrm{N}_{\mathrm{t}}$-related band at $\sim 620 \mathrm{~cm}^{-1}$ relative to the unmodified $\mathrm{N}_{\mathrm{d}}$ peak at $815 \mathrm{~cm}^{-1}$, along with a general decrease in the intensity of the high frequency bands at $\sim 1013$ and $1150 \mathrm{~cm}^{-1}$ respectively. These decreases in peak intensity could be due to distortion of the constituent structural units caused by thermal relaxation, although the PON species with $\mathrm{N}_{\mathrm{d}}$ remain unaffected by increasing temperature. This infers that, as nitrogen is released from the glass network because of oxidation, $\mathrm{N}_{\mathrm{t}}$ speciation is more sensitive to oxidation than $\mathrm{N}_{\mathrm{d}}$.

The lack of sharp crystalline peaks in the spectra of the sample treated at $T_{\mathrm{a}}<T_{\mathrm{g}}$ indicates that oxygen is restricted from diffusing into and reacting with the glass network, as either the oxide layer does not form on the powder particles, or it is smaller than the penetration depth of the laser probe $(<0.6 \mu \mathrm{m})$. For $T_{\mathrm{a}} \geq T_{\mathrm{g}}$, new sharp bands emerge ascribed to crystalline sodium phosphate (see details below) and detected at 263, $398,658,681,751,1009$, and $1092 \mathrm{~cm}^{-1}$ for the samples treated at $T_{\mathrm{g}}$ and $1.05 T_{\mathrm{g}}$, with additional bands emerging at higher $T_{\mathrm{a}}$. It is thus noted that whereas the spectra of the powdered samples treated at $T_{\mathrm{g}}$ and $1.05 T_{\mathrm{g}}$ are similar, additional crystalline phases appear in the samples treated at $1.1 T_{\mathrm{g}}$ to $1.2 T_{\mathrm{g}}$. That is, new 
sharp bands appear in the entire frequency range of the spectra, most notably at 263, 358, 658, 681, and 1234 $\mathrm{cm}^{-1}$ (Fig. 3a).

The crystallization behavior of the oxidized powdered samples is evident in the X-ray diffraction patterns, shown in Fig. 4. Crystallization occurs in the samples treated in air at $T_{\mathrm{a}} \geq T_{g}$, and, in contrast to spectroscopic experiments, the XRD pattern gives the evidence for the crystallization also in the sample heat-treated at $0.9 T_{\mathrm{g}}$. According to the JCPDS data file, the possible crystalline phases are mainly sodium phosphates, e.g. metaphosphates $\left(\mathrm{NaPO}_{3}\right.$, cyclic $\left.\left(\mathrm{NaPO}_{3}\right)_{3,6}\right)$, polyphosphates $\left(\mathrm{Na}_{4} \mathrm{P}_{2} \mathrm{O}_{7}\right.$ and $\left.\mathrm{Na}_{5} \mathrm{P}_{6} \mathrm{O}_{10}\right)$ and orthophosphate $\mathrm{Na}_{3} \mathrm{PO}_{4}$. It should also be noted that the diffraction peaks of nitrogen-containing sodium phosphate crystals, i.e., nitride phosphates such as $\mathrm{Na}_{4} \mathrm{P}_{4} \mathrm{O}_{9} \mathrm{~N}_{2}$ or $\mathrm{Na}_{6} \mathrm{P}_{6} \mathrm{O}_{15} \mathrm{~N}_{2}$, or amide $\mathrm{NaPO}_{2}\left(\mathrm{NH}_{2}\right)$, exist at similar angles as for the pure oxide phases.

The crystallinity of the powdered sample increases with increasing $T_{\mathrm{a}}$, implying that the fraction of amorphous phase decreases, and thus this could be the main reason for the $C_{\mathrm{p}}$ decrease seen in Fig. 1a. The $C_{\mathrm{p}}$ jump would totally disappear if glass phase were not present. The sharp decrease in $C_{\mathrm{p}}$ after the overshoot for the samples treated at $0.9 T_{\mathrm{g}}$ to $T_{\mathrm{g}}$, with no evidence of crystalline peaks on the Raman spectra (Fig. 3a), could be related to a partial breakdown of the oxynitride network caused by a sudden release of nitrogen upon heating. In contrast, the samples treated at $1.15-1.2 T_{\mathrm{g}}$ do not exhibit the sharp decrease in $C_{\mathrm{p}}$. This could be attributed to the fact that majority of nitrogen has already been released during the prior isothermal treatment, and hence, the structural network has been partially disassociated and stabilized.

In the case of bulk glass samples, even for longer treatment duration, e.g., $20 \mathrm{~h}$ at $T_{\mathrm{a}}=T_{\mathrm{g}}$, significant weaker crystallization, i.e. lower crystal fraction in the surface layer of the oxidized bulk compared to the powdered samples is observed. There is no evidence of surface crystallization for shorter oxidation durations of $t_{\mathrm{a}}=30 \mathrm{~min}$ at $T_{\mathrm{a}}>T_{\mathrm{g}}$ (red curve in Fig. 3b). Moreover, no changes in transparency (e.g., due to formation of white oxide scale on the surface) are visible for the sample treated at $T_{\mathrm{a}}<1.25 T_{\mathrm{g}}$. Above this temperature, the samples become opaque. For higher temperature treatments, the bulk samples present sharp crystalline peaks appearing at different wavenumbers in contrast to the powdered samples, i.e., peaks at 304, 370, 638, 1274, and $1329 \mathrm{~cm}^{-1}$ (Fig. 3b). Although resembling those observed on the powdered samples oxidized at similar $T_{\mathrm{a}}$, differ in peak position and intensity especially in the low frequency regime. Similar behavior was observed upon heat-treating a MgSiON oxynitride glass in both powder and bulk form [42], which confirms 
that the crystallization behavior is influenced by the variation in specific surface area, yielding a different crystallization behavior.

\subsection{Dynamic heating}

In situ high-temperature Raman measurements have been conducted on the bulk glasses in order to directly monitor the thermally-induced structural changes arising in the oxynitride glass as a function of atmosphere: in air (Fig. 5a) and $\mathrm{N}_{2}$ (Fig. 5b), respectively. During the in situ Raman experiments in both air and $\mathrm{N}_{2}$, no sharp peaks characteristic of crystalline phases are observed, contrary to the ex situ experiments of isothermally heat-treated samples (Fig. 3b). This can be explained by the fact that the sample was subjected to a dynamic heating, with only short isothermal holds $(1 \mathrm{~min})$ at each temperature. Moreover, no visible decrease of transparency was observed in dynamically heated sample in $\mathrm{N}_{2}$, whereas dynamic heating in air did lead to a decreased transparency, indicating that a thin oxidized layer forms on the surface of the sample. This layer may have such small thickness that it cannot be detectable by Raman spectroscopy.

To better clarify the structural changes taking place during the dynamic heating, the analyzed in situ Raman spectra were deconvoluted. Although Raman spectroscopy only provides qualitative or semiquantitative structural information, spectral deconvolution enables an identification of the short-range order (SRO) structures involved in the thermal oxidation. To the best of our knowledge, such deconvolution has not been reported for oxynitride phosphate glasses. An example of the deconvolution with 18 Gaussian peaks is shown in Fig. 6 for the as-made $\mathrm{NaPO}_{2.25} \mathrm{~N}_{0.5}$ glass. The proposed assignments of the Raman bands are summarized in Table 1. Herein, the unambiguous assignments of the vibrational modes of phosphate and phosphorus oxynitride glass network are considered: (i) $\delta(\mathrm{O}-\mathrm{P}-\mathrm{O})$ bending network vibrations in the lowfrequency range; (ii) $v(\mathrm{P}-\mathrm{O}-\mathrm{P})$ stretching vibrations of the $\mathrm{BOs}$ along with the $\mathrm{N}_{\mathrm{d}}$ and $\mathrm{N}_{t}$ vibrations in the intermediate-frequency range; and (iii) high-frequency $v(\mathrm{O}-\mathrm{P}-\mathrm{O})$ and $\mathrm{v}(\mathrm{P}=\mathrm{O})$ stretching vibrations of NBOs mainly in $Q^{2}$ sites, along with $Q^{1}$ sites.

In this work, it is first proposed that (i) the low-frequency band is divided into three components, one of which is attributed to $\mathrm{Na}^{+}-\mathrm{O}^{-}$[24], [25], [43], [44], (ii) the band for the tri-coordinated nitrogen is separated into two bands, as suggested in related studies [21], [30], [32], [36], and (iii) the sub-peaks of the highest intensity peak in the high Raman shift range (related to $\mathrm{PO}_{2}$ sites) are attributed to characteristic tetrahedral units of oxynitride glasses, i.e., $\mathrm{PO}_{\mathrm{x}} \mathrm{N}_{\mathrm{y}}$ [21], [30], [32], [36]. By implementing these structural 
features in the deconvolution of the Raman spectra, a new and comprehensive structural model of oxynitride glass is suggested. The deconvoluted band areas and positions as a function of temperatures are shown in Fig. 7a,b for the sample heated in both air and $\mathrm{N}_{2}$, for a better comparison of the peak parameters between the two different conditions.

\subsubsection{Heating in air: effect on structure}

Fig. 5a illustrates that all the Raman bands generally shift towards lower wavenumbers with temperature upon dynamic heating in air of the NaPON glass. The most notable changes with temperature consist of the characteristic peaks of the phosphate network, i.e. the $680 \mathrm{~cm}^{-1}$ intense (P-O-P) band (peak 7 in Table 1 and Fig. 7a,b) and the $1150 \mathrm{~cm}^{-1}\left(\mathrm{PO}_{2}\right)$ band (peak 15), both decreasing in intensity and wavenumber, and both exhibiting a minimum at $773 \mathrm{~K}$ when heated in air. The changes are more pronounced for peak 15 , related to NBOs in phosphate matrix. The symmetrical mode of peak 15 , considered to be highly sensitive to the association of the counterions [45], shows a frequency shift towards lower wavenumber with increasing temperature (Fig. 7a, orange line for peak 15). This suggests temperature-induced changes in the ionic character of the $\mathrm{Na}-\mathrm{O}$ bonds between the phosphate chains, or a change in $\mathrm{Na}^{+}$coordination. Fleutot et al. [36] have previously connected the increase in $-\mathrm{O}^{-}-\mathrm{Li}^{+}$vibrational motion to a decrease in the chain length. The frequency decrease of peak 15 is more pronounced for the samples treated at $T_{\mathrm{a}}>T_{\mathrm{g}}$ compared to those treated at $T_{\mathrm{a}}<T_{\mathrm{g}}$, but accompanied by a significant reduction in area (Fig. $7 \mathrm{~b}$, orange line for peak 15), that can be also connected to a higher degree of structural ordering.

This scenario is supported by the fact that the major structural changes with temperature are observed in the low-frequency region of the spectra. The broad Raman band around 200-400 $\mathrm{cm}^{-1}$ increases in intensity on the low energy shoulder with increasing temperature during dynamic heating in air (Fig. 5a). The band is composed of three separate bands: one centered around $250 \mathrm{~cm}^{-1}$ corresponding to Na-O cation motion in ionic-type sites (peak 1) and two at 325 and $375 \mathrm{~cm}^{-1}$ belonging to $\mathrm{O}-\mathrm{P}-\mathrm{O}$ bending modes of chain and ring conformations (peak 2), respectively [30], [43], [46]. The intensity increase on the low energy side suggests a change in the cationic activity of the modifier, i.e. perturbations of the local environment of $\mathrm{Na}^{+}$or rearrangements of the phosphate chains into rings or shorter chains [24]. In the former case, it could be due to oxidation effects: either outward cationic diffusion [4], [6] or the diffusion of molecular $\mathrm{O}_{2}$ in the glassy network. The molecular oxygens can lead to formation of non-bonded oxygen sites (analogous to interstitial defects in crystalline structures). These oxygen sites might play a non-bonding role in the network upon 
oxidation, which could distort the $\mathrm{Na}^{+}$polyhedra, forming weak bonds that vibrate at such low Raman shift [24]. The existence of such sites of interstitial oxygen can be also inferred by the lack of an evident intensity increase of the $Q^{1}$ and $\mathrm{P}_{2} \mathrm{O}_{7}{ }^{4-}$ depolymerized sites typically situated around $1000 \mathrm{~cm}^{-1}$, thus implying that the structural modification caused by nitrogen depletion is irreversible, without oxygen reentering the network as a bridging anion. Ultimately, this strong temperature dependence of the $\mathrm{Na}^{+}-\mathrm{O}^{-}$vibrational modes in air could be due to the changes in the local coordination sphere of $\mathrm{Na}$, in turn due to the diffusion and incorporation of oxygen (as non-bonded anions) in the network.

There are two different vibrational modes centered at 620 and $640 \mathrm{~cm}^{-1}$ in phosphorous oxynitride structures that have been previously related to the $\mathrm{P}-\mathrm{N}<$ linkages, i.e., $\mathrm{N}_{\mathrm{t}}$ species [21], [32], [36], [47]. However, Achibat et al. [30] raised doubt about any relation between the $640 \mathrm{~cm}^{-1}$ peak and nitrogen vibration, as the mode has also been observed in $\mathrm{N}$-free oxide glasses [16]. Moreover, vibrations centered around $640 \mathrm{~cm}^{-1}$ have been observed in a devitrified sodium metaphosphate glass, ascribed to in-chain $v\left(\mathrm{PO}_{2}\right)_{\mathrm{s}}$ of polycrystalline $\mathrm{NaPO}_{3}[33]$, and also detectable in the spectrum of the nitrogen-free $\mathrm{NaPO}_{3}$ glass. It is thus inferred herein that no direct connection between $\mathrm{N}$ bonds and the $640 \mathrm{~cm}^{-1}$ peak exists, but instead the peak should be assigned to other types of vibration modes related to the O-P-O linkages, e.g., bending and torsional motions, not stretching. That is, the $\mathrm{N}_{\mathrm{t}}$ peak (generally referred to in literature as a single band at $620 \mathrm{~cm}^{-1}$ ) has here been separated into two sub-bands, i.e. one at $590 \mathrm{~cm}^{-1}$ assigned to $\mathrm{N}_{\mathrm{t}}$ with neighboring $\mathrm{N}\left(-\mathrm{N}(\mathrm{d}, \mathrm{t})-\mathrm{P}-\mathrm{N}<\right.$ type bonding, peak 4) and another at $620 \mathrm{~cm}^{-1}$ assigned to $\mathrm{N}_{\mathrm{t}}$ with neighboring $\mathrm{O}$ as the next anion $(-\mathrm{O}-\mathrm{P}-\mathrm{N}<$ type bonding, peak 5). These proposed assignments are based on the difference in electronegativity between $\mathrm{O}$ and $\mathrm{N}$ atoms, since oxygen, as a more electronegative element, would attract the electrons towards itself over the O-P-N $<$ linkages, reducing the negative charge surrounding $\mathrm{N}_{\mathrm{t}}$ and shifting it towards higher Raman shift.

Fig. $7 \mathrm{~b}$ shows that both the frequency and the area of these two $\mathrm{N}_{\mathrm{t}}$-related bands evolve in opposite manner with temperature. The area of peak 5 decreases with temperature below $T_{\mathrm{g}}$. On the other hand, that of peak 4 increases in the same temperature interval. This dependence of peak area on temperature might imply that oxidation affects the nitrogen distribution within the oxynitride network and the phosphonitride tetrahedral species, forcing the oxynitride network to be rearranged. That is, the thermal energy enables more $\mathrm{N}-\mathrm{P}-\mathrm{N}<$ bonds to form at the expense of $\mathrm{O}-\mathrm{P}<\mathrm{N}$ type bonds. This opposite behavior in both peak position and relative area of peaks 4 and 5 could explain the non-monotonic evolution of the main $630 \mathrm{~cm}^{-1}$ band in 
Fig. 5a. A similar behavior has been observed during in situ high temperature Raman measurements on phosphoniobate glass, in which niobate $\mathrm{NbO}_{6}$ polyhedra with different degrees of distortions corresponding to two Raman bands exhibit an opposite dependence on temperature in peak intensity, also ascribed to "nanometric phase separation" [48]. The same trend observed here might suggest a similar scenario, in which structural separation at nanoscale takes place within the oxynitride sub-network. We also note that peak 4 is the only vibration band, which yields an upshift to higher wavenumbers with temperature (Fig. 7a), although the wavenumbers are found to decrease with temperature. This could be due to shortening of bond length in the corresponding polyhedral unit or a decrease in the intertetrahedral angle. Another explanation of the opposite behavior of peaks 4 and 5 could be due to the transformation of the O-P-N network into O-P-O network, indicating a preferential depletion of the nitrogen in $\mathrm{N}_{\mathrm{t}}$ sites within the $-\mathrm{O}-\mathrm{P}<\mathrm{N}$ type bondages.

In contrast, peak 9 related to $\mathrm{N}_{\mathrm{d}}$ can be represented by only one Gaussian peak, due to the symmetry of the peak (Fig. 6). This di-coordinated nitrogen peak shows a systematic decrease in intensity as a function of temperature (Fig. 5a). Its evolution with temperature is more clearly shown in Fig. 7, where it is clear that Nd is continuously downshifting in frequency, while also decreasing in peak area until $T_{\mathrm{a}} \approx T_{\mathrm{g}}$. These observations are somewhat contradicting the Raman result of the isothermally-treated bulk glasses (Fig. 3b), in which the $\mathrm{N}_{\mathrm{d}}$ peak appears to remain unchained with the thermal treatment. These changes in the nitrided specifications suggest a minor oxidation of the oxynitride phosphate network, which is, however, not accompanied by formation of any crystalline oxide layer detectable by Raman. This lack of spectroscopic detection can be explained by the focusing depth of the Raman excitation line, which should be around 0.6 $\mu \mathrm{m}$ for a $532 \mathrm{~nm}$ laser and a 0.55 numerical aperture, and a possible oxide layer thinner than this penetration depth.

For phosphate glasses, the high frequency Raman region contains the characteristic fingerprints of symmetric stretching O-P-O of the non-bridging oxygens (peak 15) with respect to the phosphate chain [49], thus providing valuable structural information in relation to speciation of tetrahedral units present in the network. For phosphorus oxynitride glasses, an increase in the nitrogen content within the phosphate network leads to a decrease in the amplitude of the main peak 15 at $1150 \mathrm{~cm}^{-1}$ coupled with a deformation on both sides of the band. This large broadening gives rise to the characteristically broad band of the symmetric stretching of the doubly bonded oxygen, $v(\mathrm{P}=\mathrm{O})_{\mathrm{s}}$ (peak 18), along with the asymmetric stretching of the other NBOs, i.e., $v\left(\mathrm{PO}_{2}\right)_{\text {as }}$ at $1220 \mathrm{~cm}^{-1}$ (peak 17). Based on this, the sub-peaks on both neighboring sides of 
the $\mathrm{PO}_{2}$ intense peak are assigned to $\mathrm{N}$-related vibrational modes in the $\mathrm{PO}_{4-\mathrm{y}} \mathrm{N}_{\mathrm{y}}$ tetrahedral units formed upon nitridation. However, the question is whether these phosphonitride modes are Raman active. Du et al. [50] performed first-principle calculations on LiPON materials, providing valuable information on the vibrational modes related to bridging $\mathrm{N}$ and reported that such $\mathrm{N}$-related modes appear at $850\left(\mathrm{~N}_{\mathrm{d}}\right.$ modes), 1060 , and $1120 \mathrm{~cm}^{-1}$ (unattributed modes) for $\mathrm{Li}_{2} \mathrm{PO}_{2} \mathrm{~N}$. Therefore, these findings confirm that $\mathrm{N}$-containing structures are active and have a vibrational response in the high Raman shift range.

A new structural model is thus proposed based on the Raman deconvolution of the NaPON glass subjected to dynamic heating. The peaks at 1080,1150 , and $1175 \mathrm{~cm}^{-1}$ could be attributed to the motions of the $\mathrm{X}-\mathrm{P}-\mathrm{N}$ and $\mathrm{X}=\mathrm{O}, \mathrm{N}$ linkages in oxynitride sites. The lowest energy sub-peak at $1080 \mathrm{~cm}^{-1}$ (peak 12) would then be connected to local vibrations of $\mathrm{PO}_{3} \mathrm{~N}$ sites with a configuration similar to $Q^{1}$ or surrounding the $Q^{1}$ tetrahedra generated after the chain breakages during nitrogen incorporation [21], with orthophosphate sites clearly detectible at $970-1015 \mathrm{~cm}^{-1}$ on the pristine NaPON glass (Fig. 3a bottom). The neighboring peak

at $1150 \mathrm{~cm}^{-1}$ (peak 13) would then be related to $\mathrm{PO}_{3} \mathrm{~N}$ or $\mathrm{PO}_{2} \mathrm{~N}_{2}$ sites with $Q^{2}$ type-configuration or surrounded by $Q^{2}$ polyhedra. Finally, the sub-peak on the higher energy side of the $\mathrm{PO}_{2}$ peak can be ascribed to $\mathrm{PO}_{3} \mathrm{~N}$ or $\mathrm{PO}_{2} \mathrm{~N}_{2}$ sites with configuration of a higher polymerized structure similar to $Q^{3}$ (peak 16). These three peaks related to the nitride tetrahedra are denoted as $Q^{1}(\mathrm{O}, \mathrm{N}), Q^{2}(\mathrm{O}, \mathrm{N})$, and $Q^{3}(\mathrm{O}, \mathrm{N})$. Analogous analyses have been made on SiAlON oxynitride glasses, with reactions of the type $Q^{3}(\mathrm{Si})+\mathrm{N} \rightarrow Q^{4}(\mathrm{O}, \mathrm{N})$, in which $\mathrm{N}$ atoms transform the $Q^{3}\left(\mathrm{SiO}_{4}\right.$ with one $\left.\mathrm{NBO}\right)$ into $Q^{4}\left(\mathrm{SiO}_{2} \mathrm{~N}_{2}\right.$ with two NBOs) [51]. Peak 16, related to the most polymerized species, appears to be most sensitive to dynamic heat-treatment in air. These oxynitride sites move to lower Raman shifts, while peaks 12 and 13 remain mostly unaffected (Fig. 7). Peak 16 also exhibits a highly non-monotonic temperature dependence. This result might indicate that the nitrogen depletion upon oxidation in air takes place by involving the bridging nitrogens involved in the more polymerized sites of $Q^{3}(\mathrm{O}, \mathrm{N})$ and $Q^{2}(\mathrm{O}, \mathrm{N})$ tetrahedra. The small increase of the peak 7 area (related to BOs) at $T_{\mathrm{a}}>T_{\mathrm{g}}$ supports this interpretation.

\subsubsection{Heating in nitrogen: effect on structure}

The dynamic heating in $\mathrm{N}_{2}$ leads to less pronounced structural changes compared to those occurring in air (Fig. 5b) and the main peaks exhibit minima at different temperatures than during dynamic heating in air. The low-frequency range of the spectra shows the same changes in nitrogen as in air, but the magnitude of 
the changes as a function of temperature is smaller. In turn, the spectrum of the sample heated in $\mathrm{N}_{2}$ shows a pronounced temperature effect for the N-related peaks.

As shown in more detail in Fig. 7a (blue lines for peaks 4 and 5), the positions of peaks 4 and 5 related to $\mathrm{N}_{\mathrm{t}}$ vibrational modes exhibit the same behavior in nitrogen as it does in air, i.e., peak 4 shifts towards lower wavenumber with temperature, while peak 5 shifts towards higher wavenumber. The same temperature dependence is observed for peak 7, i.e., the center of the peak decreases gradually with temperature. The gradual identical decrease in area of peak 15 with temperature in both air and $\mathrm{N}_{2}$ suggests that the $\mathrm{Na}^{+}-\mathrm{O}^{-}$ interaction is not the main reason for the reduction of the $(\mathrm{PO})_{2}$ signal as postulated above, given the unmodified behavior of peak 1 during heating in $\mathrm{N}_{2}$ in comparison to air. Rather it infers to other local changes occurring in its vicinity, possibly referring to a higher degree of structural ordering of the phosphate polyhedra. Moreover, the temperature dependence of N-related peaks 5 and 9 suggests that the N-P average bond in both configurations lengthen upon heating in $\mathrm{N}_{2}$ atmosphere, as both peaks shift to lower frequencies with increasing temperature. Peak 4 exhibits the same behavior on heating in both $\mathrm{N}_{2}$ and air in terms of the shift to higher wavelengths. The three-coordinated nitrogen configurations in heat treated samples are analyzed as follows: (i) bond lengths of $\mathrm{N}_{\mathrm{t}}$ increase when oxygen is its next nearest neighbor, as suggested by the shift towards lower wavenumbers of peak 5 (Fig. 7a) at $T_{\mathrm{a}}<T_{\mathrm{g}}$, after which it remains unchanged; (ii) peak 5 is more sensitive to the heating atmosphere than peak 4. Peak 9 of $\mathrm{N}_{\mathrm{d}}$, although following the same temperature dependence of the peak position as seen during dynamic heating in air, the peak area remains unchanged over the entire temperature regime for $\mathrm{N}_{2}$ treatment, in contrast to the area peak evolution upon heating in air. The Raman downshift can thus be explained based on the thermal relaxation, resulting in bond length increase, while the steady peak area of peak 9 indicates that di-coordinated nitrogen is a stable nitride configuration upon heating in nitrogen atmosphere.

Considering the $Q^{\mathrm{n}}(\mathrm{O}, \mathrm{N})$ groups, both peaks 13 and 16 show a non-systematic area variation with temperature (Fig. 7b). Based on all the discussions above, it can be stated that the heat-treatment (especially in air) increases the mobility of the structural species and enables structural re-arrangements, with preference for the tri-coordinated nitrogen to bond to the $-\mathrm{N}-\mathrm{P}-\mathrm{N}<$ linkages rather than $-\mathrm{O}-\mathrm{P}-\mathrm{N}<$. Nano crystalline phases could occur in the sample, leading to a decrease of the Raman peak areas. However, the nanocrystalline phase is not detectable by the techniques employed here, although it is reported that nano-scale phase separation could occur in NaPON and LiPON oxynitride glasses [16]. 


\section{Conclusions}

The oxidation resistance of a sodium oxynitride phosphate glass with N/P ratio $\sim 0.5$ has been investigated by subjecting both powder and bulk samples to dynamic and isothermal treatments in air and in $\mathrm{N}_{2}$. The heattreatment temperature $\left(T_{\mathrm{a}}\right)$ dependence of $T_{\mathrm{g}}$ for the powdered glass samples in air has been explored, showing that oxidation begins around $T_{\mathrm{g}}$, and $T_{\mathrm{g}}$ decreases with $T_{\mathrm{a}}$ when $T_{\mathrm{a}}>T_{\mathrm{g}}$. For the bulk glass, $T_{\mathrm{g}}$ decreases only slightly even after long time heat-treatment, becoming constant after $4 \mathrm{~h}$ of heating in air. The crystalline structures as a result of the isothermal oxidation differ slightly between the powder and bulk samples, but both are dominated by metaphosphate phase.

The changes in the oxynitride network structure as probed by Raman spectroscopy are more pronounced in the powdered samples even at lower $T_{\mathrm{a}}$ than in the bulk samples. Based on deconvolution of the in situ high-temperature Raman spectra, a structural model has been proposed to account for the structural changes caused by the dynamic heating, and to assign specific vibrational modes to oxynitride $Q^{\mathrm{n}}(\mathrm{P}, \mathrm{N})_{4}$ tetrahedral species. The strong temperature dependence of the $\mathrm{Na}^{+}-\mathrm{O}^{-}$vibration modes for the samples treated in air implies the changes in the local coordination sphere of $\mathrm{Na}$ due to the diffusion and incorporation of free oxygen into the network. This is evidenced by the lack of depolymerization of phosphate tetrahedral units. An opposite temperature dependence is observed in both peak position and relative area of the $\mathrm{N}_{\mathrm{t}}$-related sub-peaks for $-\mathrm{O}-\mathrm{P}-\mathrm{N}<$ linkage and $-\mathrm{N}-\mathrm{P}-\mathrm{N}<$ type linkage.

$\mathrm{N}_{\mathrm{t}}$ in $-\mathrm{O}-\mathrm{P}-\mathrm{N}<$ type bonding is more sensitive to the heating environment than that of $\mathrm{N}_{\mathrm{t}}$ with nitrogen as neighboring atom, while $\mathrm{N}_{\mathrm{d}}$ area peak remains completely unchanged during heating in $\mathrm{N}_{2}$. The peak related to oxynitride polymerized species $Q^{3}(\mathrm{O}, \mathrm{N})$ is most sensitive to dynamic heat-treatment in air. Large differences between dynamic heating in air and $\mathrm{N}_{2}$ has been found in peak area of $Q^{1}(\mathrm{P}, \mathrm{N})$ tetrahedral units, suggesting that depolymerization takes place but within the oxynitride sub-network. Non-systematic structural fluctuations of $Q^{2}$ and $Q^{3}(\mathrm{P}, \mathrm{N})$ sites, as well as that of $\mathrm{N}_{\mathrm{t}}$ sub-bands, suggest a nano-phase separation within the network. This work suggests that the oxynitride glasses should be used in the temperature range up to the glass transition temperature, above which the structural stability is lost.

\section{Acknowledgements}


G.L.P., Y.Y., and M.M.S. acknowledge funding from Lundbeck Foundation. F.M. acknowledges funding for project MAT2013-48246-C2-1-P from Ministerio de Economía y Competitividad (MINECO) of Spain. G.L.P. thanks Rene M. Thomsen for helpful discussions. 


\section{References}

[1] S. Sakka, “Oxynitride glasses,” Ann. Rev. Mater. Sci., vol. 16, pp. 29-46, 1986.

[2] A. Bachar, C. Mercier, A. Tricoteaux, A. Leriche, C. Follet, and S. Hampshire, "Bioactive oxynitride glasses: Synthesis, structure and properties,” J. Eur. Ceram. Soc., vol. 36, no. 12, pp. 2869-2881, 2016.

[3] J. Rocherullé, P. Verdier, and Y. Laurent, "Preparation and properties of gadolinium oxide and oxynitride glasses," Mater. Sci. Eng. B2, vol. 2, no. 4, pp. 265-268, Apr. 1989.

[4] M. Desmaison-Brut and J. Desmaison, "Oxidation behavior of an oxynitride glass in the system CaSi-Al-O-N,” J. Non-Cryst. Solids, vol. 105, pp. 323-329, 1988.

[5] D. Manessis and H. Du, "Oxidation kinetics of crystalline silicon oxynitride," in Mat. Res. Soc. Symp. Proc., 1997, vol. 446, pp. 127-132.

[6] A. Sharafat and B. Jonson, "Oxidation behavior of nitrogen rich AE-Si-O-N glasses (AE=Ca, Sr, Ba)," in Processing, Properties, and Applications of Glass and Optical Materials: Ceramic Transactions, vol. 231, A. K. Varshneya et al., Eds. 2011, pp. 173-177.

[7] R. R. Wusirika, "Oxidation Behavior of Oxynitride Glasses," J. Am. Ceram. Soc., vol. 68, no. 11, p. C-294-C-297, 1985.

[8] C. O. Meara, G. L. Dunlop, and R. Pompe, "Formation, Crystallisation and Oxidation of Selected Glasses in the Y-Si-Al-O-N System," J. Eur. Ceram. Soc., vol. 8, 1991.

[9] M. Sebai, C. Penot, P. Goursat, K. Liddell, D. P. Thompson, E. Nestor, R. Ramesh, and S. Hampshire, "Oxidation Resistance of Nd-Si-Al-O-N Glasses and Glass-Ceramics," J. Eur. Ceram. Soc., vol. 18, pp. 169-182, 1998.

[10] M. Sebai, J. Sjöberg, P. Goursat, E. Nestor, R. Flynn, R. Ramesh, and S. Hampshire, "Oxidation Behaviour of Yttrium and Neodymium Oxynitride Glasses,” J. Eur. Ceram. Soc., vol. 15, pp. 10151024, 1995.

[11] R. K. Brow and C. G. Pantano, "Oxidation resistant sol-gel derived silicon oxynitride thin films," Appl. Phys. Lett., vol. 48, no. 1, pp. 27-29, 1986.

[12] Y. Murakami and H. Yamamoto, "Properties of Oxynitride Glasses in the Ln-Si-Al-O-N Systems (Ln = Rare-Earth )," J. Ceram. Soc. Japan, vol. 102, no. 3, pp. 231-236, 1994.

[13] F. Tessier, L. Le Gendre, F. Cheviré, R. Marchand, and A. Navrotsky, "Thermochemistry of a new 
class of materials containing dinitrogen pairs in an oxide matrix," Chem. Mater., vol. 17, no. 13, pp. 3570-3574, 2005.

[14] F. Muñoz, L. Pascual, A. Durán, J. Rocherullé, and R. Marchand, "Oxidation behaviour of Li-Na-PbP-O-N oxynitride phosphate glasses,” J. Eur. Ceram. Soc., vol. 26, no. 8, pp. 1455-1461, 2006.

[15] M. Rajaram and D. E. Day, "Preparation and properties of oxynitride glasses made from $27 \mathrm{R}_{2} \mathrm{O}$ 20BaO-3 $\mathrm{Al}_{2} \mathrm{O}_{3}-50 \mathrm{P}_{2} \mathrm{O}_{5}$ glass," J. Non-Cryst. Solids, vol. 102, pp. 173-180, 1988.

[16] G. L. Paraschiv, F. Muñoz, L. R. Jensen, Y. Yue, and M. M. Smedskjaer, "Impact of nitridation of metaphosphate glasses on liquid fragility," J. Non-Cryst. Solids, vol. 441, pp. 22-28, 2016.

[17] F. Muñoz, F. Agulló-Rueda, L. Montagne, R. Marchand, A. Durán, and L. Pascual, "Structure and properties of $(25-\mathrm{x} / 2) \mathrm{Li}_{2} \mathrm{O} \cdot(25-\mathrm{x} / 2) \mathrm{Na}_{2} \mathrm{O} \cdot \mathrm{xPbO} \cdot 50 \mathrm{P}_{2} \mathrm{O}_{5}$ metaphosphate glasses," J. Non-Cryst. Solids, vol. 347, pp. 153-158, Nov. 2004.

[18] M. Reidmeyer, M. Rajaram, and D. Day, "Preparation of phosphorus oxynitride glasses," J. NonCryst. Solids, vol. 85, pp. 186-203, 1986.

[19] Y. Yue, "Characteristic temperatures of enthalpy relaxation in glass," J. Non-Cryst. Solids, vol. 354, no. 12-13, pp. 1112-1118, Feb. 2008.

[20] "Multivariate Curve Resolution Homepage." [Online]. Available: http://www.mcrals.info/. [Accessed: 20-May-2001].

[21] B. C. Bunker, D. R. Tallant, C. A. Balfe, R. J. Kirkpatrick, G. L. Turner, and M. R. Reidmeyer, "Structure of Phosphorus Oxynitride Glasses," J. Am. Ceram. Soc., vol. 70, no. 9, pp. 675-681, 1987.

[22] L. Popović, D. De Waal, and J. C. A. Boeyens, "Correlation between Raman wavenumbers and P-O bond lengths in crystalline inorganic phosphates," J. Raman Spectrosc., vol. 36, no. 1, pp. 2-11, 2005.

[23] P. Stoch, A. Stoch, M. Ciecinska, I. Krakowiak, and M. Sitarz, "Structure of phosphate and ironphosphate glasses by DFT calculations and FTIR/Raman spectroscopy," J. Non-Cryst. Solids, vol. 450, pp. 48-60, 2016.

[24] B. N. Nelson and G. J. Exarhos, "Vibrational spectroscopy of cation-site interactions in phosphate glasses," J. Chem. Phys., vol. 71, no. 7, p. 2739, 1979.

[25] G. Le Saout, P. Simon, F. Fayon, A. Blin, and Y. Vaills, "Raman and Infrared Study of $(\mathrm{PbO})_{\mathrm{x}}\left(\mathrm{P}_{2} \mathrm{O}_{5}\right)_{(1-\mathrm{x})}$ Glasses," J. Raman Spectrosc., vol. 33, pp. 740-746, 2002. 
[26] J. Koo, B.-S. Bae, and H.-K. Na, "Raman spectroscopy of copper phosphate glasses," J. Non-Cryst. Solids, vol. 212, pp. 173-179, 1997.

[27] J. J. Hudgens, R. K. Brow, D. R. Tallant, and S. W. Martin, "Raman spectroscopy study of the structure of lithium and sodium ultraphosphate glasses," J. Non-Cryst. Solids, vol. 223, no. 1-2, pp. 21-31, 1998.

[28] S. Chakraborty and A. K. Arora, "Temperature evolution of Raman spectrum of iron phosphate glass,"Vib. Spectrosc., vol. 61, pp. 99-104, 2012.

[29] R. K. Brow, "Review : The structure of simple phosphate glasses," J. Non-Cryst. Solids, vol. 263264, pp. 1-28, 2000.

[30] T. Achibat and R. Marchand, "Disorder and ramification in phosphorus oxynitride glasses," J. NonCryst. Solids, vol. 144, pp. 145-150, 1992.

[31] D. E. Day, "Structural role of nitrogen in phosphate glasses," J. Non-Cryst. Solids, vol. 112, pp. 7-14, 1989.

[32] T. Pichonat, C. Lethien, N. Tiercelin, S. Godey, E. Pichonat, P. Roussel, M. Colmont, and P. Alain, "Further studies on the lithium phosphorus oxynitride solid electrolyte," Mater. Chem. Phys., vol. 123, no. 1, pp. 231-235, 2010.

[33] G. J. Exarhos and W. M. Risen, "Raman Study of Isothermal Devitrification Kinetics of NaPO3 Glass,”pp. 401-405, 1974.

[34] N. Mascaraque, A. Durán, F. Muñoz, and G. Tricot, "Structural Features of LiPON Glasses Determined by 1D and 2D 31 P MAS NMR," Int. J. Appl. Glas. Sci., pp. 1-11, May 2015.

[35] A. Le Sauze, L. Montagne, G. Palavit, F. Fayon, and R. Marchand, "X-ray Photoelectron Spectroscopy and Nuclear Magnetic Resonance structural study of phosphorus oxynitride glasses , LiNaPON,”J. Non-Cryst. Solids, vol. 263\&264, pp. 139-145, 2000.

[36] B. Fleutot, B. Pecquenard, H. Martinez, M. Letellier, and A. Levasseur, "Investigation of the local structure of LiPON thin films to better understand the role of nitrogen on their performance," Solid State Ionics, vol. 186, no. 1, pp. 29-36, 2011.

[37] A. Le Sauze, L. Montagne, G. Palavit, and R. Marchand, "Nitridation of alkali metaphosphate glasses: a comparative structural analysis of the $\mathrm{Na}-\mathrm{P}-\mathrm{O}-\mathrm{N}$ and $\mathrm{Li}-\mathrm{Na}-\mathrm{P}-\mathrm{O}-\mathrm{N}$ systems," J. NonCryst. Solids, vol. 293-295, pp. 81-86, Nov. 2001. 
[38] H. Liu, M. M. Smedskjaer, H. Tao, L. R. Jensen, X. Zhao, and Y. Yue, "A medium range order structural connection to the configurational heat capacity of borate-silicate mixed glasses," Phys. Chem. Chem. Phys., vol. 18, p. 10887, 2016.

[39] D. J. M. Burkhard, "Relation between oxidation/crystallization and degassing upon reheating of basalt glass from Kilauea, Hawaii," Mineral. Mag., vol. 69, no. 2, pp. 103-117, 2005.

[40] C. Hermansen, R. E. Youngman, J. Wang, and Y. Yue, "Structural and topological aspects of borophosphate glasses and their relation to physical properties," J. Chem. Phys., vol. 142, no. 18, 2015 .

[41] N. Mascaraque, J. Luis, G. Fierro, A. Durán, and F. Muñoz, "An interpretation for the increase of ionic conductivity by nitrogen incorporation in LiPON oxynitride glasses," Solid State Ionics, vol. 233, pp. 73-79, 2013.

[42] C. T. Shaw, "The crystallization of glasses in the Mg-Si-O-N system," Ph.D. Thesis, University of California, 1980.

[43] M. A. Carrillo Solano, M. Dussauze, P. Vinatier, L. Croguennec, E. I. Kamitsos, R. Hausbrand, and W. Jaegermann, "Phosphate structure and lithium environments in lithium phosphorus oxynitride amorphous thin films," Ionics (Kiel)., vol. 22, no. 4, pp. 471-481, 2016.

[44] R. L. Frost, W. Martens, P. A. Williams, and J. T. Kloprogge, "Raman and infrared spectroscopic study of the vivianite-group phosphates vivianite, baricite and bobierrite," Mineral. Mag., vol. 66, no. 6, pp. 1063-1073, 2002.

[45] S. Mamedov, D. Stachel, M. Soltwisch, and D. Quitmann, "Local environment and dynamics of $\mathrm{PO}_{4}$ tetrahedra in Na-Al-PO 3 glasses and melts," J. Chem. Phys., vol. 123, no. 12, p. 124515, 2005.

[46] G. J. Exarhos, "Vibrational studies of glass tructure and localized interactions," in Proceedings of the International Symposium on Structure and Bonding in Non-Crystalline Solids, 1986, pp. 203-217.

[47] E. Guille, G. Vallverdu, Y. Tison, D. Be, I. Baraille, and P. Angot, "Possible existence of a monovalent coordination for nitrogen atoms in $\mathrm{Li}_{x} \mathrm{PO}_{\mathrm{y}} \mathrm{N}_{\mathrm{z}}$ solid electrolyte: Modeling of $\mathrm{X}^{-}$ray Photoelectron Spectroscopy and Raman spectra," J. Phys. Chem. C, vol. 119, p. 23379, 2015.

[48] Y. Takahashi, K. Nakamura, M. Osada, and T. Fujiwara, "Structural relaxation and quasi-elastic ferroelectric and ion-conducting phases," Sci. Rep., vol. 741, no. 2, pp. 1-6, 2012.

[49] J. Swenson, A. Matic, A. Brodin, L. Borjesson and W. S. Howells, "Structure of mixed alkali 
phosphate glasses by neutron diffraction and Raman spectroscopy," Phys. Rev. B, vol. 58, no. 17, pp. 331-337, 1998.

[50] Y. A. Du and N. A. W. Holzwarth, "First-principles study of LiPON and related solid electrolytes," Phys. Rev. B, vol. 81, no. 18, p. 184106, 2010.

[51] E. Dolekcekic, M. J. Pomeroy, and S. Hampshire, "Structural characterisation of Er-Si-Al-O-N glasses by Raman spectroscopy,” J. Eur. Ceram. Soc., vol. 27, no. 2-3, pp. 893-898, Jan. 2007.

[52] S. Damodaraiah, V. Reddy Prasad, S. Babu, and Y. C. Ratnakaram, "Structural and luminescence properties of $\mathrm{Dy}^{3+}$ doped bismuth phosphate glasses for greenish yellow light applications," Opt. Mater. (Amst)., vol. 67, pp. 14-24, 2017.

[53] M. R. Reidmeyer and D. E. Day, "Phosphorus oxynitride glasses," J. Non-Cryst. Solids, vol. 181, pp. 201-214, 1995.

[54] J. E. Pemberton, L. Latifzadeh, J. P. Fletcher, and S. H. Risbud, "Raman spectroscopy of calcium phosphate glasses with varying $\mathrm{CaO}$ modifier voncentrations," Chem. Mater., vol. 3, no. 13, pp. 195200, 1991.

[55] R. K. Brow and D. R. Tallant, "Structural design of sealing glasses," J. Non-Cryst. Solids, vol. 222, pp. 396-406, 1997. 


\section{Figures and tables}

Table 1. Proposed assignment of Raman peaks in the $\mathrm{NaPO}_{2.25} \mathrm{~N}_{0.5}$ glass.

\begin{tabular}{|c|c|c|c|}
\hline $\begin{array}{l}\text { Peak } \\
\text { no. }\end{array}$ & $\begin{array}{l}\text { Wavenumber } \\
\left(\mathrm{cm}^{-1}\right)\end{array}$ & Assignment & Refs. \\
\hline 1 & $250-270$ & $\mathrm{Na}^{+}-\mathrm{O}^{-}$stretching vibration in ionic-type sites & $\begin{array}{l}\text { [30], [43], } \\
{[46],[52]}\end{array}$ \\
\hline 2 & $323-328$ & \multirow{2}{*}{$\begin{array}{l}\delta(\mathrm{O}-\mathrm{P}-\mathrm{O}) \text { bending motions of chain and ring } \\
\text { conformations }\end{array}$} & \multirow{2}{*}{$\begin{array}{l}{[23],[24],} \\
{[30],[45]}\end{array}$} \\
\hline 3 & $375-380$ & & \\
\hline 4 & $590-595$ & $\mathrm{~N}_{\mathrm{t}}$ in $-\mathrm{N}(\mathrm{d}, \mathrm{t})-\mathrm{P}-\mathrm{N}<$ type bonding & this work \\
\hline 5 & $620-624$ & $\mathrm{~N}_{\mathrm{t}}$ in $-\mathrm{O}-\mathrm{P}-\mathrm{N}<$ type bonding* & $\begin{array}{l}{[30],[41],} \\
{[53]}\end{array}$ \\
\hline 6 & $637-640$ & $\delta(\mathrm{P}-\mathrm{O}-\mathrm{P})_{\mathrm{s}}$ bending (and rocking) motions & $\begin{array}{l}\text { [23], [28], } \\
{[33],[47]}\end{array}$ \\
\hline 7 & $676-681$ & $\mathrm{v}(\mathrm{P}-\mathrm{O}-\mathrm{P})_{\mathrm{s}}$ symmetric stretching & {$[54],[55]$} \\
\hline 8 & $702-714$ & $\mathrm{v}(\mathrm{P}-\mathrm{O}-\mathrm{P})_{\text {as }}$ asymmetric stretching by short chains & {$[54],[55]$} \\
\hline 9 & $805-812$ & $\mathrm{P}=\mathrm{N}-$ bonding & {$[31]$} \\
\hline 10 & $972-977$ & Orthophosphate sites $\left(\mathrm{PO}_{4}\right)^{3-}$ & {$[21],[23]$} \\
\hline 11 & $1009-1013$ & Pyrophosphate sites $\left(\mathrm{P}_{2} \mathrm{O}_{7}\right)^{4-}$ & $\begin{array}{l}{[21],[22],} \\
{[31]}\end{array}$ \\
\hline 12 & $1079-1081$ & $\begin{array}{l}\text { Oxynitride } \mathrm{P}(\mathrm{O}, \mathrm{N})_{4} \text { species with configuration similar to or } \\
\text { surrounded by } Q^{1}, Q^{1}(\mathrm{O}, \mathrm{N})\end{array}$ & this work \\
\hline 13 & $1114-1120$ & $\begin{array}{l}\text { Oxynitride } \mathrm{P}(\mathrm{O}, \mathrm{N})_{4} \text { species with configuration similar to or } \\
\text { surrounded by } Q^{2}, Q^{2}(\mathrm{O}, \mathrm{N})\end{array}$ & this work \\
\hline 14 & $1130-1133$ & $\begin{array}{l}v\left(\mathrm{PO}_{2}\right)_{\text {s,as }} \text { stretch with mixed symmetric and asymmetric } \\
\text { character in } Q^{2} \text { and } Q^{1}\end{array}$ & {$[25],[47]$} \\
\hline 15 & $1148-1151$ & out-of-chain $v\left(\mathrm{PO}_{2}\right)_{\mathrm{s}}$ symmetric stretch in $Q^{2}$ sites & $\begin{array}{l}{[24],[25],} \\
{[27]}\end{array}$ \\
\hline 16 & $1172-1181$ & $\begin{array}{l}\text { Oxynitride } \mathrm{P}(\mathrm{O}, \mathrm{N})_{4} \text { species with /configuration similar to } \\
\text { or surrounded by } Q^{3}, Q^{3}(\mathrm{O}, \mathrm{N})\end{array}$ & $\begin{array}{l}\text { this work, } \\
\text { [51] }\end{array}$ \\
\hline 17 & $1213-1220$ & $v\left(\mathrm{PO}_{2}\right)_{\text {as }}$ asymmetric stretching & {$[25]$} \\
\hline 18 & $1250-1265$ & $\mathrm{v}(\mathrm{P}=\mathrm{O})_{\mathrm{s}}$ symmetric stretching & {$[22],[25]$} \\
\hline
\end{tabular}

* referred to as generic $-\mathrm{P}-\mathrm{N}<$ vibrations centered $\sim 630 \mathrm{~cm}^{-1}$ 

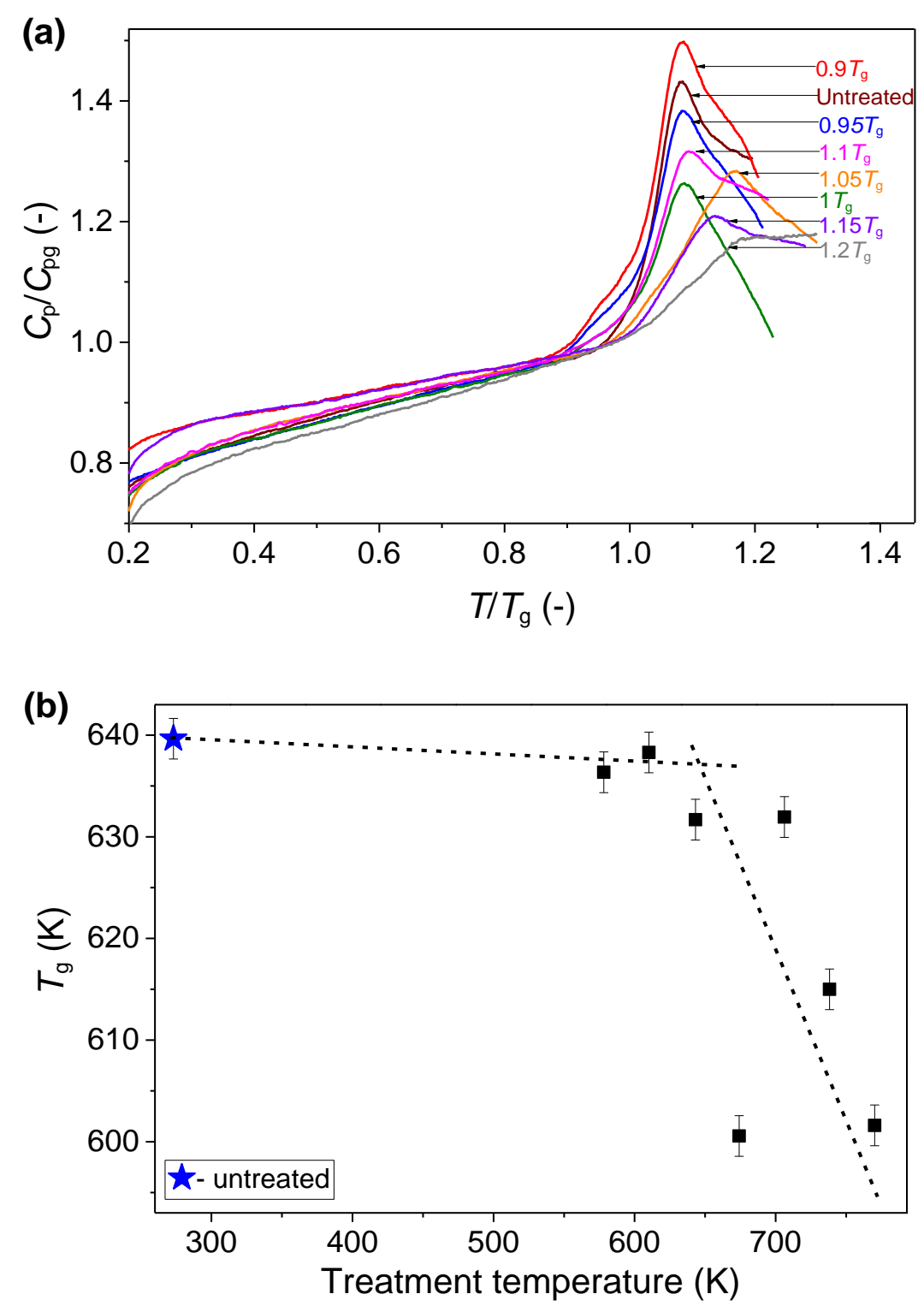

Figure 1. (a) Heat capacity curves and (b) glass transition temperature $\left(T_{\mathrm{g}}\right)$ of the powdered $\mathrm{NaPO}_{2.25} \mathrm{~N}_{0.5}$ glass samples after heat-treatment in air at different temperature $\left(0.9-1.2 T_{\mathrm{g}}\right)$ for 1 hour. The dashed lines in (b) represent a guide for the eye to emphasize the change in slope at temperature below and above $T_{\mathrm{g}}$. 


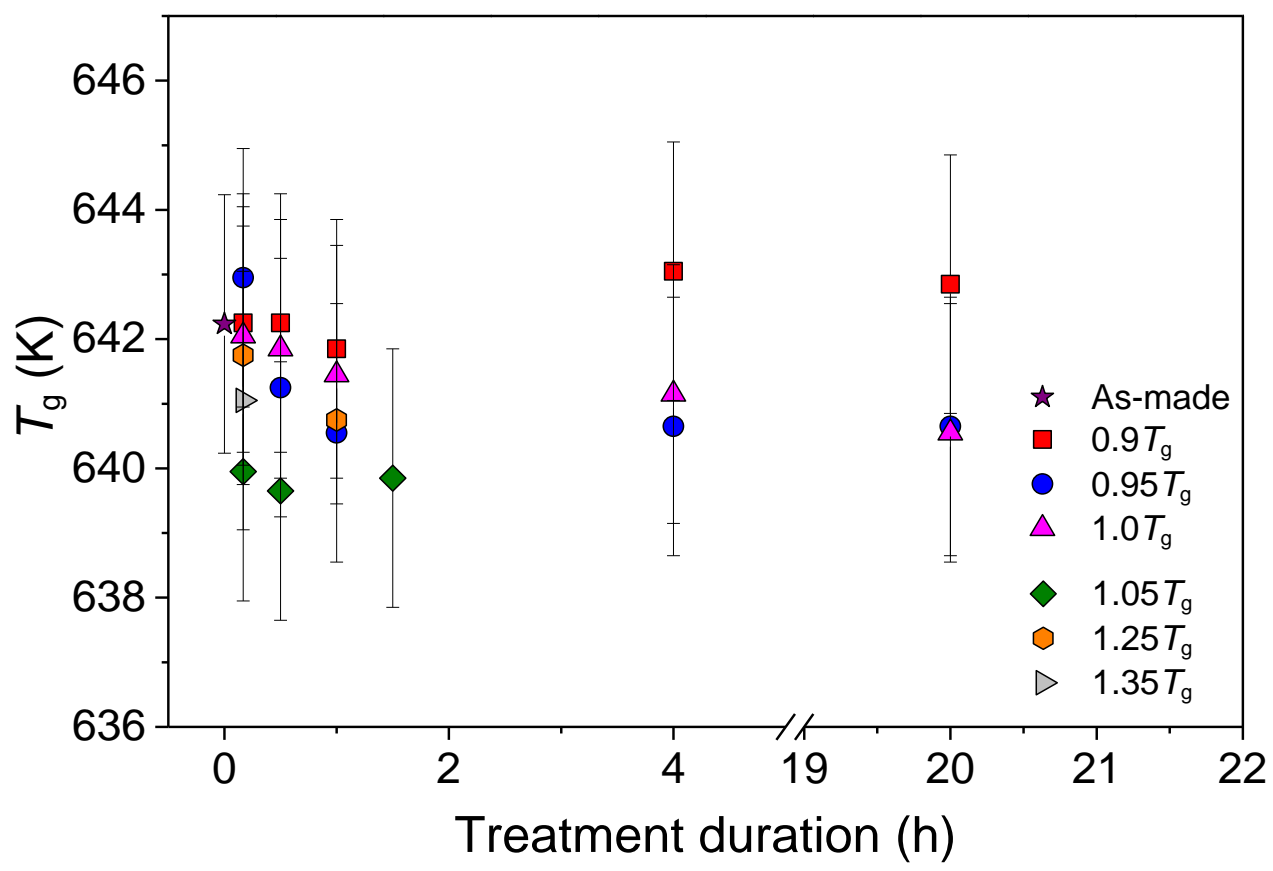

Figure 2. Glass transition temperature $\left(T_{\mathrm{g}}\right)$ of the $\mathrm{NaPO}_{2.25} \mathrm{~N}_{0.5}$ bulk glass samples as a function of the isothermal heat-treatment duration at different temperatures performed in air. 

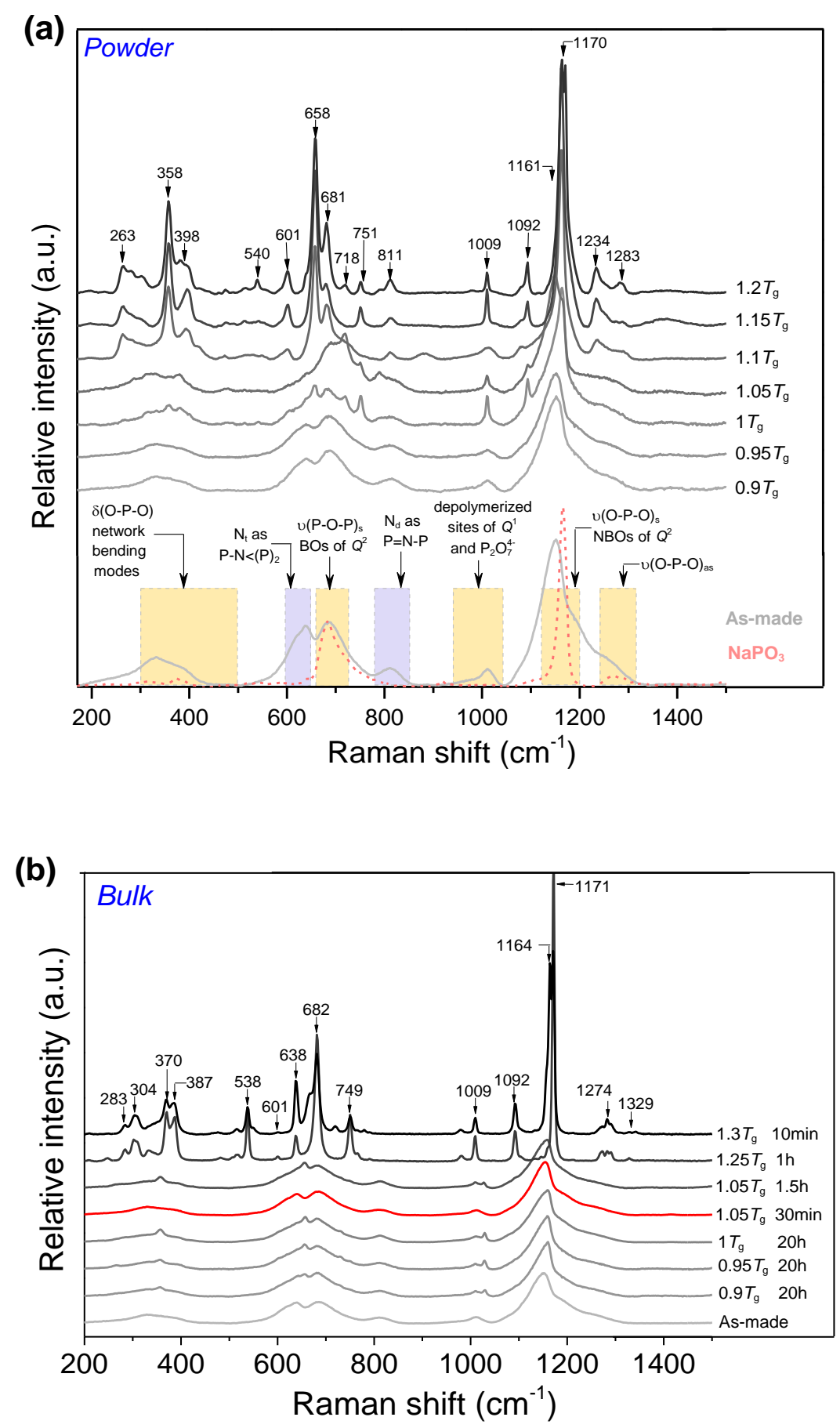

Figure 3. Ex situ Raman spectra of the $\mathrm{NaPO}_{2.25} \mathrm{~N}_{0.5}$ glass heat-treated isothermally in air: (a) powdered samples treated for $t_{\mathrm{a}}=1 \mathrm{~h}$ at different temperatures; (b) bulk samples treated at different temperatures and durations. Characteristic vibrational modes associated with the phosphate network (orange highlights) and structural features caused by anionic substitution with nitrogen (purple highlight) are shown at the bottom of (a) on the as-prepared sample and nitrogen-free $\mathrm{NaPO}_{3}$ spectra. The red line in (b) denotes the difference in treatment durations for the sample heated at $1.05 T_{\mathrm{g}}$. Spectra are shifted vertically for clarity. 


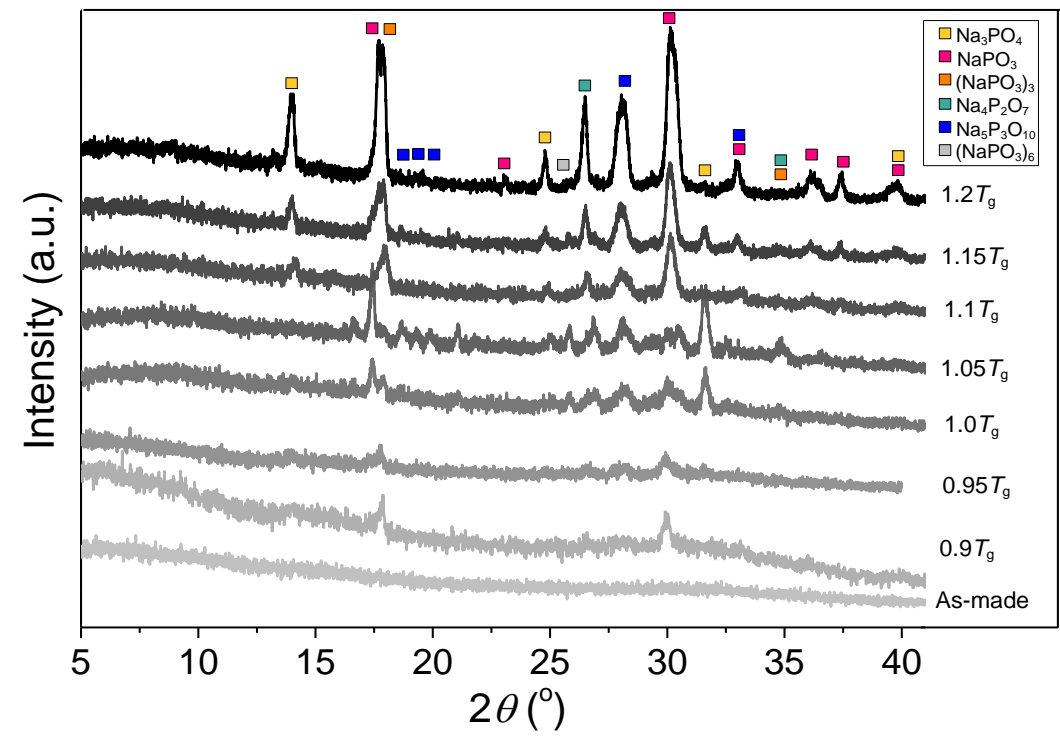

Figure 4. X-ray diffraction patterns of powdered $\mathrm{NaPO}_{2.25} \mathrm{~N}_{0.5}$ glass samples heat-treated for $t_{\mathrm{a}}=1$ at different temperatures $\left(T_{\mathrm{a}}=0.9-1.2 T_{\mathrm{g}}\right)$ in air. Spectra are shifted vertically for clarity. 
(a)

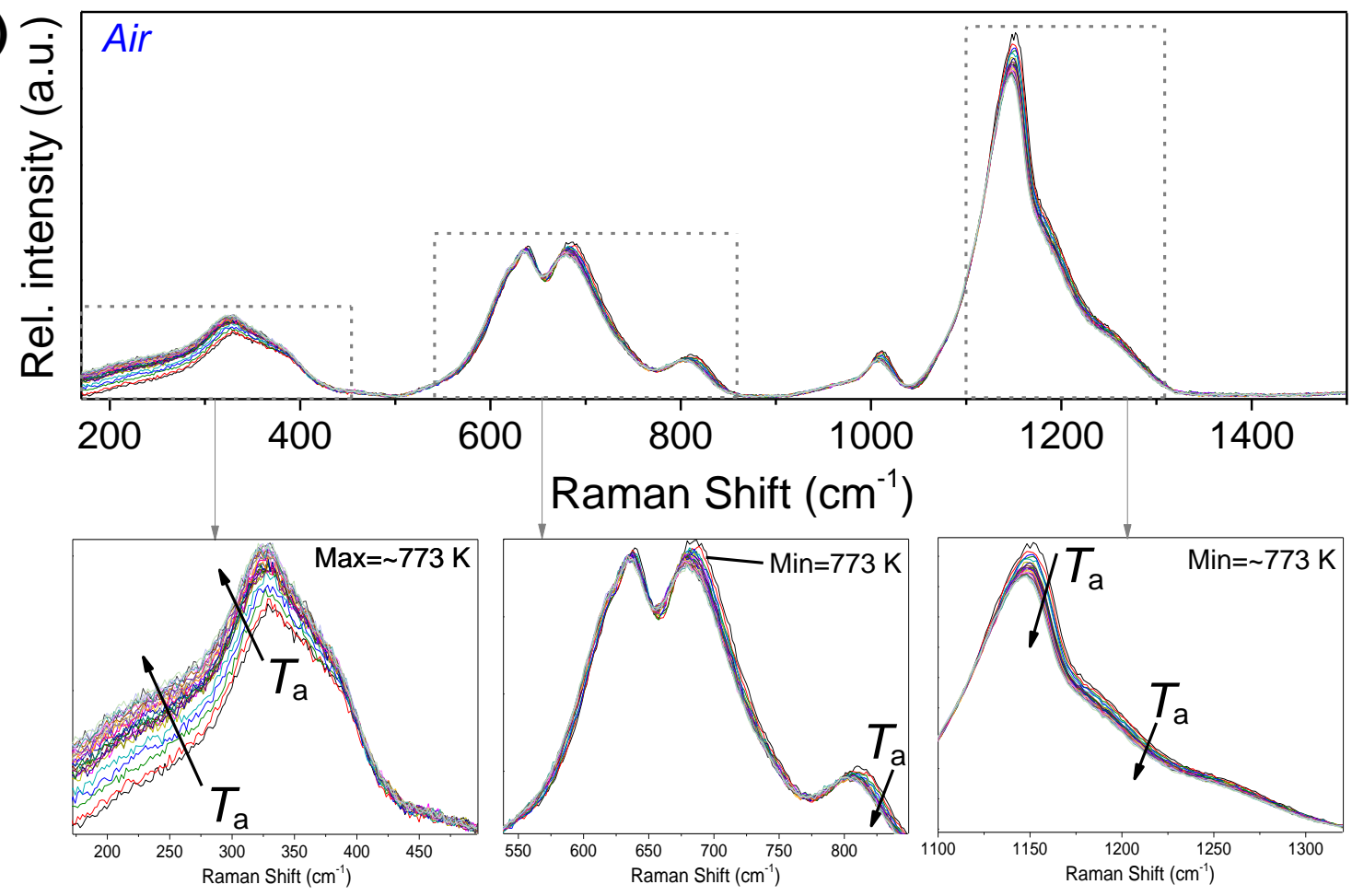

(b)
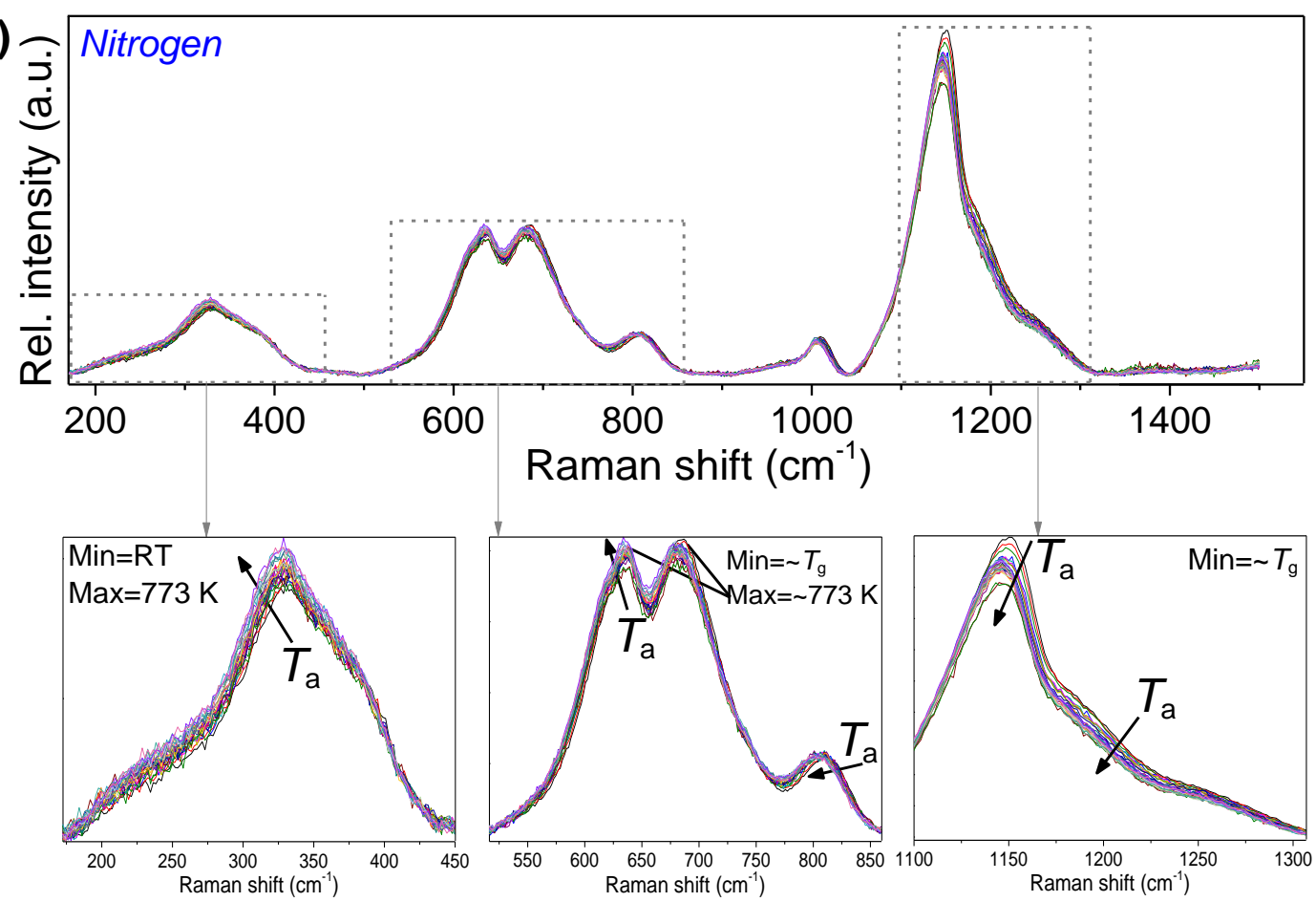

Figure 5. In situ high-temperature Raman spectroscopy measurements of the bulk glass sample in (a) in atmospheric air and (b) in nitrogen. The heating rate is $10 \mathrm{~K} / \mathrm{min}$, with $1 \mathrm{~min}$ isothermal holds at each temperature in the range from room temperature to $773 \mathrm{~K}$. The arrows denote the direction of peak evolution with increasing temperature. The three main bands have been enlarged below the spectra for clarity. 


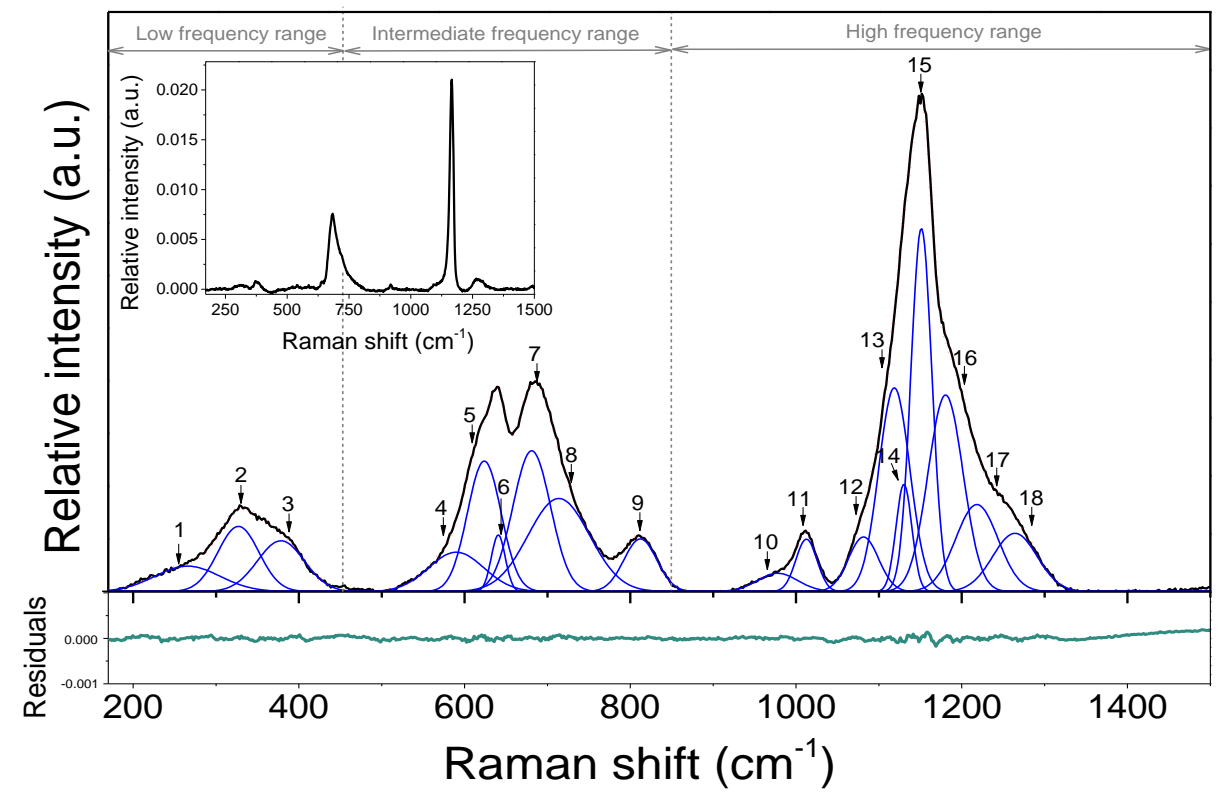

Figure 6. Deconvoluted Raman spectrum of the bulk $\mathrm{NaPO}_{2.25} \mathrm{~N}_{0.5}$ glass measured at room temperature in atmospheric air. Blue lines denote the deconvoluted components, the red line denotes the sum of the model, the black line is the measured Raman spectra, and the green line represents the fit residual. The spectrum is separated into low frequency $\left(170-450 \mathrm{~cm}^{-1}\right)$, intermediate frequency $\left(550-850 \mathrm{~cm}^{-1}\right)$, and high frequency ranges $\left(950-1300 \mathrm{~cm}^{-1}\right)$. Inset: Raman spectrum of the oxide glass $\mathrm{NaPO}_{3}[16]$. 

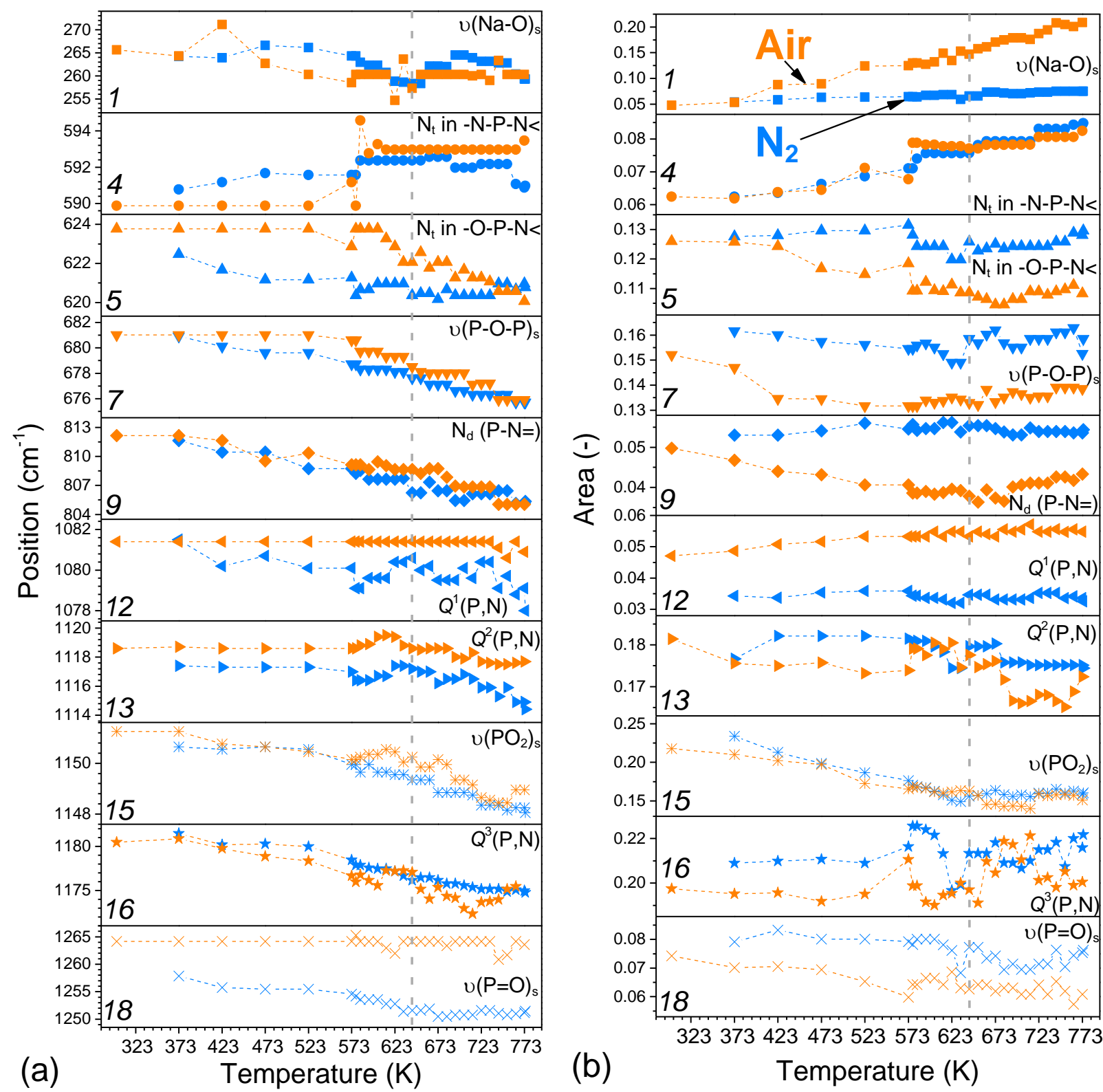

Figure 7. Temperature dependence of the position (a) and area (b) of the deconvoluted peaks of in situ temperature Raman spectra acquired in atmospheric air (orange) and nitrogen (blue). The number in each sub-figure refers to the peak number given in Fig. 6. Different types of bonding units are indicated in each sub-figure, such as phosphate-related vibrations: $v\left(\mathrm{Na}^{+}-\mathrm{O}^{-}\right)_{\mathrm{s}}, \mathrm{v}(\mathrm{P}-\mathrm{O}-\mathrm{P})_{\mathrm{s}}, \mathrm{v}(\mathrm{O}-\mathrm{P}-\mathrm{O})_{\mathrm{s}}$ units in $Q^{2}$, and $v(\mathrm{P}=\mathrm{O})_{\mathrm{s}}$ unit, nitrogen-related vibrations: $\mathrm{N}_{\mathrm{t}}$ in $-\mathrm{N}_{(\mathrm{d}, \mathrm{t})}-\mathrm{P}-\mathrm{N}<, \mathrm{N}_{\mathrm{t}}$ in $-\mathrm{O}-\mathrm{P}-\mathrm{N}<, \mathrm{P}=\mathrm{N}-$, nitrided tetrahedral species with configuration of $Q^{1}(\mathrm{O}, \mathrm{N}), Q^{2}(\mathrm{O}, \mathrm{N})$, and $Q^{3}(\mathrm{O}, \mathrm{N})$. 